\title{
DIRECT VOLTAGE CONTROL IN GRIDS WITH INTERMITTENT SOURCES USING UPFC
}

\author{
Silvangela. L. S. Lima, Robson F. S. Dias, Edson H. Watanabe \\ Universidade Federal do Rio de Janeiro - Electrical Eng. Dept. - COPPE, Rio de Janeiro, Brasil \\ email: liliam@coe.ufrj.br, dias@coe.ufrj.br, watanabe@coe.ufrj.br
}

\begin{abstract}
This paper proposes the use of a circuit with topology similar to a Unified Power Flow Controller (UPFC) for direct voltage control in electric grids with highly intermittent generation sources such as wind generators. The variable characteristics of these sources strongly affect the voltage profile in the grids. The objective of this paper is to show through a conceptual analysis that it is possible to obtain precise and fast voltage control at the PCC by using a UPFC. It is shown that the UPFC rating is smaller than that of a Static Synchronous Compensator (STATCOM) or Static Var Compensator (SVC), which should be necessary for indirect voltage control. The UPFC does not have limitation due to the number of operation per day as in the case of transformers with on load tap changer. The UPFC based on single-phase Voltage Sourced Converter (VSC) is analyzed and the series converter is connected directly to the grid without transformer. It controls the voltage independently in each phase, therefore balancing it, if necessary. Simulation results using PSCAD/EMTDC are presented to confirm all these advantages of the use of UPFC for direct voltage control. The models used in this work are classic and well validated, being sufficient to prove the principles proposed.
\end{abstract}

Keywords - Direct Voltage Control (DVC), Indirect Voltage Control (IVC), Static Synchronous Compensator (STATCOM), Wind Generator (WG), Unified Power Flow Controller (UPFC).

\section{INTRODUCTION}

The integration of a significant amount of wind generators (WG) in the distribution network may have a considerable impact on its voltage profile. The increasing number of wind turbines connected to the distribution system and their generation intermittency may cause significant voltage fluctuation at the Point of Common Coupling (PCC). Therefore, it is necessary to control the voltage in these systems to avoid the violation of its allowable levels

The voltage limits may impose a limitation on the increasing penetration of WGs in distribution systems. It is common to have these generators connected to distribution systems of rural areas where the PCC presents relatively high short circuit impedance. According to Laaksonen, Saari e Komulainen [1], this kind of grid generally has dominant resistive impedance, and in this case, the voltage control based on reactive power compensation may be ineffective or

Manuscript received 03/02/2014; revised 07/04/2014 accepted for publication 19/07/2014, by recommendation of the Special Section Editor Mário L. da S. Martins. expensive [2], [3]. The use of OLTC-Transformer (On-Load Tap Changer Transformer) may not be a viable solution due to a large number of tap changes during a relatively short time due to the intermittent characteristics of the wind power. Therefore, in this work the idea is to study a solution for the cases where mechanical contacts are not used. Naturally, reconductoring these grid maybe a solution as the grid will turn stronger. However, this solution is also not considered here. In some cases, reconductoring is too expensive.

As a solution for a fast continuous voltage control in grids with highly fluctuating voltage profile, the authors propose in this work the use of an UPFC based on single-phase VSC for direct voltage control in weak distribution grids. The UPFC is able to perform direct voltage control without the limitation of the number of operation as in the case of OLTC-Transformer. Moreover, it can be used to balance three-phase voltages, if they are unbalanced. The UPFC may enable more generation from the intermittent sources.

The use of a circuit topology similar to a UPFC based on single-phase VSC to voltage control were proposed by the authors in [4], [5]. The direct voltage control using the UPFC for voltage control in weak grids with intermittent sources is presented in [3], [6]. This paper is based on [6] with some small added explanations to improve its content.

\section{VOLTAGE PROFILE IN DISTRIBUTION SYSTEMS}

A large amount of wind generators have been connected in the distribution systems. According to [7], distributed generators cannot actively regulate voltage at the PCC, and they shall not cause voltage to violate steady-state limits, typically between $0.95 \mathrm{pu}$ and $1.05 \mathrm{pu}$. The operation of distributed generators in distribution grids may still result in voltage regulation problems, such as voltage fluctuations, if precautions are not taken [7].

To illustrate the voltage rise regulation problem due to the power injection, Figure 1 shows an equivalent circuit of a WG connected to a PCC in a distribution grid. WG generally is connected to the grid as controlled current source, at unity power factor, which allows the maximum extraction of energy from wind. The circuit in Figure 1 represents a distribution line impedance $\left(\dot{Z}_{\text {Line }}\right)$, an ideal voltage source $\left(\dot{V}_{1}\right)$ which represents the grid Thevenin equivalent voltage at the substation, and a WG as a current source $\left(I_{G}\right)$. The impedance $\dot{Z}_{L}$ represents the impedance load at PCC. The grid voltage is $13.8 \mathrm{kV}$ and the system data are: $\dot{Z}_{\text {Line }}=$ $(0.502+j 0.129) \Omega / \mathrm{km}$ that corresponds to a line impedance value of a medium voltage grid with a ratio $R / X \approx 4.0$ and $\dot{Z}_{L}=(50.0+j 12.44) \Omega$ that corresponds to $27 \%$ of the base impedance, with a base power equal to 1.0 MVA. 


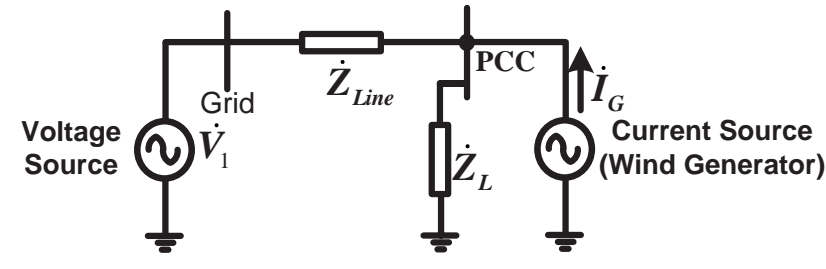

Fig. 1. Equivalent circuit of a WG connected to a feeder in a distribution grid.

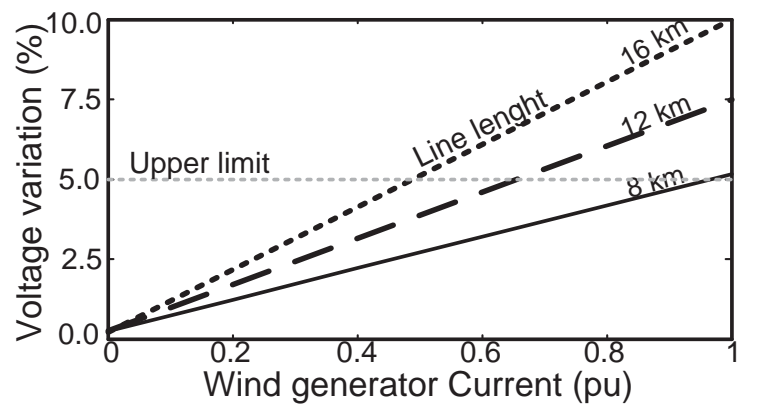

Fig. 2. PCC voltage as a function of WG current.

The steady-state PCC voltage is given by:

$$
\dot{V}_{P C C}=\frac{\dot{Z}_{L}}{\dot{Z}_{\text {Line }}+\dot{Z}_{L}} \dot{V}_{1}+\frac{\dot{Z}_{\text {Line }}}{\dot{Z}_{\text {Line }}+\dot{Z}_{L}} \dot{Z}_{L} \dot{I}_{G}
$$

where $\dot{I}_{G}$ is the phasor of the current injected by WG. Through 1 is done a simplified approach, but it serves to validate the concept discussed in this work.

Figure 2 shows the PCC voltage rise due to the injection of active power by the WG, assuming that $\dot{V}_{1}=1 \mathrm{pu}$ and the system power base is the same as the WG rating power. The voltage variation depends on the impedance of the line. It can be noted that larger voltage variations at PCC occur when the line impedance has larger values, i.e., small short-circuit ratio at PCC. The figure also shows that if the maximum voltage variation is limited to $5 \%$ of the nominal voltage, the current injected by the WG is limited to a maximum value of $0.5 \mathrm{pu}$, for the $16-\mathrm{km}$ line.

\section{VOLTAGE CONTROL IN DISTRIBUTION SYSTEMS}

The voltage control in distribution system is normally performed by a voltage regulator installed at the feeders. Conventionally there are two ways to control the voltage [2]: the Indirect Voltage Control (IVC) by controlling reactive power or active power and the Direct Voltage Control (DVC) by using transformers with on load tap changers.

\section{A. Equipment for Indirect Voltage Control (IVC)}

In the IVC strategy, voltage is controlled by the reactive power injection. In this case, the compensation can be performed in the conventional way using capacitors or inductors shunt connected to the circuit. Another solution for the voltage control can be based on power electronics shunt compensation [2], [8], resulting in a more precise voltage control. The STATCOM is one equipment able to provide voltage support to the power system in the vicinity of the busbar to which it is connected. It has been successfully applied to a number of projects [9], [10]. This controller is designed for dynamic voltage control against voltage fluctuations and dips, as well as for reduction of flicker phenomena [9], [11], [12], but it can be naturally used for steady-state voltage control. Thyristor-based compensators like SVC or TSC (Thyristor Switched Capacitor) can also be used.

\section{B. Equipment for Direct Voltage Control (DVC)}

In DVC strategy, additional equipment is installed in the grid to directly control the voltage. It can be done by changing the transformer tap or by adding a series voltage source to the busbar voltage. The OLTC-transformer is normally used in distribution grid for this purpose. Voltage control by this transformer is performed maintaining its tap adjusted to ensure the voltage level along the feeders within pre-set limits. The main characteristics and operation modes of a OLTC are presented in [13]. Its disadvantage is the slow response time [13] and the limited number of operation per day due to the mechanical damage and its life shortening as well the discrete nature of the control.

The DVC also can be done by the UPFC. It has several possible operation modes [14]. One of them is the voltage control mode. In this mode, the voltage synthesized by the series connected VSC has the phase angle equal to $0^{\circ}$ or $180^{\circ}$ with respect to the PCC voltage and then its magnitude is continuously controlled. Simulation results of a conventional UPFC used to control the output voltage of a substation are presented in [2]. But, the use of singlephase converters, proposed by the authors in [3]- [6], permits voltage compensation even under unbalanced operation, and each phase voltage can be controlled independently to balance the grid voltage, Figure 3 shows a basic line diagram of the UPFC based on single-phase VSCs (UPFC - 1 $\phi$ ). For a three-phase system, three single-phase back-to-back VSCs are necessary. Each shunt VSC 1 has a coupling transformer in its AC side, similar to the conventional UPFC. In this case, as shown in Figure 3, the series VSCs were connected in series with the secondary windings of the grid transformer avoiding coupling transformer. When the neutral connection is internal and not accessible, the series VSCs can be directly connected in series with the grid or they can be connected in series with the transformer windings in delta connection. However, these connections are not evaluated here.

\section{COMPARISON BETWEEN EQUIPMENT RATING FOR IVC AND DVC}

This section presents a comparative analysis between IVC and DVC in terms of controller rating.

Figure 4 shows a simplified equivalent circuit of a WG connected to a feeder in a distribution grid. This circuit is referred to the secondary winding and the compensation current $\dot{I}_{C o m p}$ is not the same of the real circuit. The WG is modeled as a current source, $\dot{I}_{G}$, operating at unity power factor, i.e. it injects only active power, representing a typical 


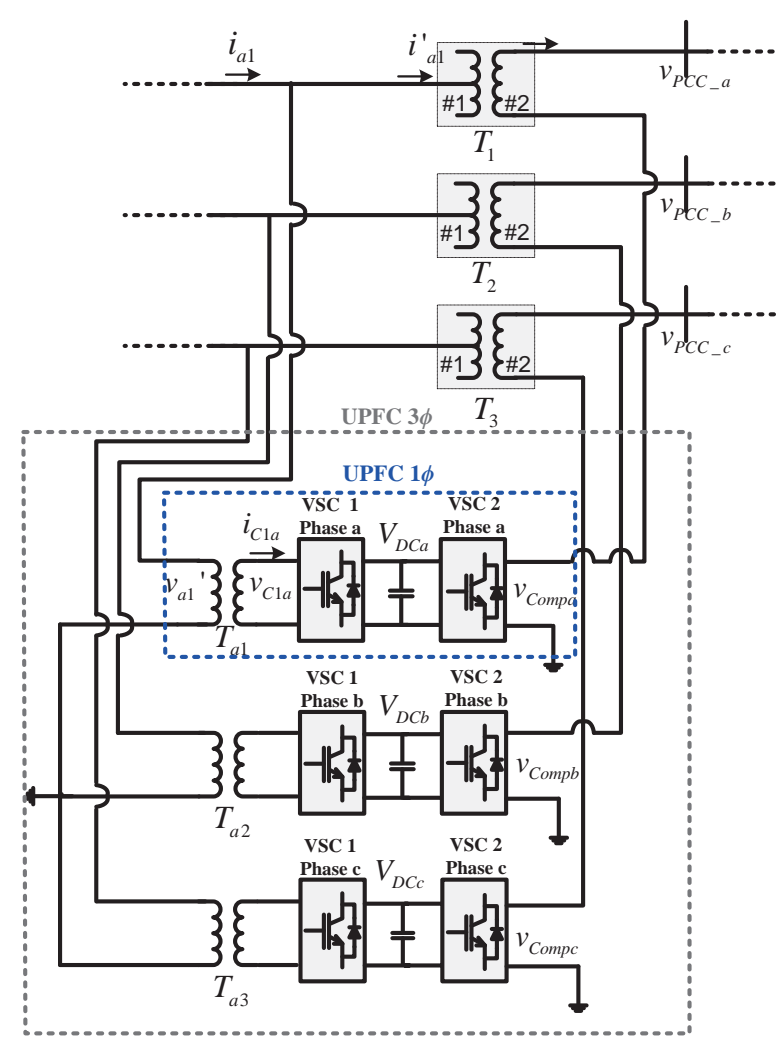

Fig. 3. Basic line diagram of the UPFC based on single-phase VSCs.

situation of wind energy production in the market. The feeder is modeled as a series impedance since it is a short line. A STATCOM is connected to the PCC to perform the IVC controlling the reactive current $\left(\dot{I}_{C o m p}\right)$. The voltage source is fixed at $\dot{V}_{1}=1 \mathrm{pu}$.

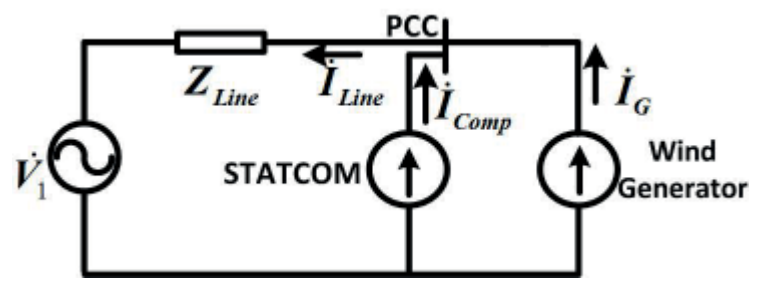

Fig. 4. Simplified equivalent circuit of WG connected to a feeder in a distribution grid, including a STATCOM equivalent circuit for IVC.

The Kirchhoff equation at PCC can be expressed as:

$$
\frac{\dot{V}_{P C C}}{Z_{\text {Line }}}-\frac{\dot{V}_{1}}{Z_{\text {Line }}}-\dot{I}_{G}=\dot{I}_{\text {Comp }} .
$$

If the phasors in (2) are replaced by their respective complex variables, the following system is obtained:

$$
\frac{V_{P C C}}{Z_{\text {Line }}} \cos \left(\phi-\theta_{Z_{\text {Line }}}\right)-\frac{V_{1}}{Z_{\text {Line }}} \cos \left(\phi-\theta_{Z_{\text {Line }}}\right)-
$$

$$
\begin{gathered}
\frac{V_{P C C}}{Z_{\text {Line }}} \sin \left(\phi-\theta_{Z_{\text {Line }}}\right)-\frac{V_{1}}{Z_{\text {Line }}} \sin \left(\phi-\theta_{Z_{\text {Line }}}\right)- \\
I_{G} \sin (\phi)=I_{\text {Comp }} \sin (\phi \pm(\pi / 2))
\end{gathered}
$$

where $I_{C o m p}$ and $\phi$ are the magnitude and phase angle of the compensating current. Solving (3) and (4) using Newton's Method Figure 5 can be obtained. This figure shows the compensation current necessary for IVC to keep the PCC voltage at $1.0 \mathrm{pu}$, as a function of the generated current by the WG in distribution lines with resistive characteristics $(R / X \approx$ 4.0). Figure 5 indicates that for IVC the compensation current may be as high as $1.6 \mathrm{pu}$, which is an unworkable value.

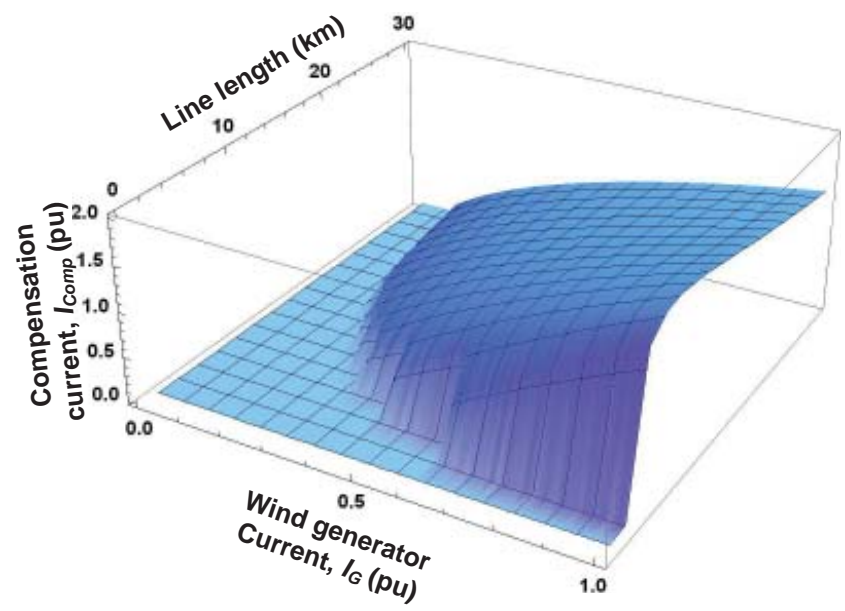

Fig. 5. Compensation current $\left(I_{C o m p}\right)$ for IVC as a function of the injected current by the WG $\left(I_{G}\right)$ and resistive line impedance.

Figure 6 shows the same equivalent circuit shown in Figure 4, but with DVC using a UPFC represented by a shunt current source and a series voltage source exchanging the same active power. The UPFC performs the DVC synthesizing a compensation voltage $\left(\dot{V}_{C o m p}\right)$ in series with the PCC voltage in order to maintain this voltage at a desired value. The series voltage source may exchange active power with the grid, and this power is injected to or absorbed by the grid through the current source $\left(\dot{I}_{s h}\right)$ keeping the power balance in the UPFC. In this analysis, it is also considered that the compensation keeps the voltage at PCC in the range of $\pm 3 \%$ of the reference value. Note that this voltage variation range could be zero, but the size of the UPFC could be greater than with the range of $\pm 3 \%$.

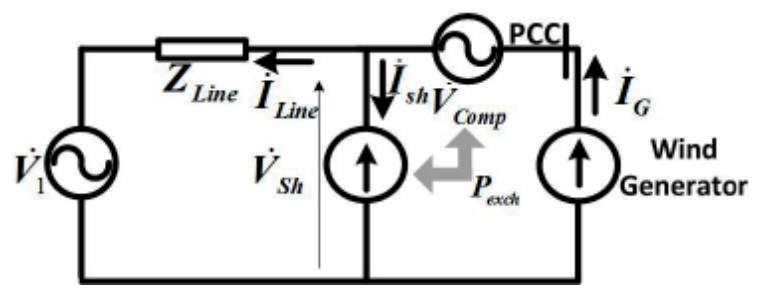

Fig. 6. Equivalent circuit of a distribution grid with a WG connected at the PCC and the UPFC for direct voltage control.

The grid performance including the DVC performed by the 
UPFC is expressed as:

$$
\begin{gathered}
\dot{V}_{S h}=\dot{V}_{1}+\dot{Z}_{\text {Line }}\left(\dot{I}_{G}-\dot{I}_{S h}\right) \\
\dot{V}_{P C C}= \pm \dot{V}_{C o m p}+\dot{V}_{S h} \\
\dot{I}_{S h}=\left(\dot{V}_{C o m p}{ }^{*} \dot{I}_{G}\right) / \dot{V}_{S h}^{*}
\end{gathered}
$$

where $V_{C o m p}$ and $\phi$ correspond to the magnitude and phase angle of the compensation voltage. The results of a direct compensation performed by the UPFC in resistive lines $(R / X \approx 4.0)$ are shown in Figure 7 . The maximum compensation voltage obtained is lower than $0.6 \mathrm{pu}$ and the maximum shunt current is lower than $0.3 \mathrm{pu}$.

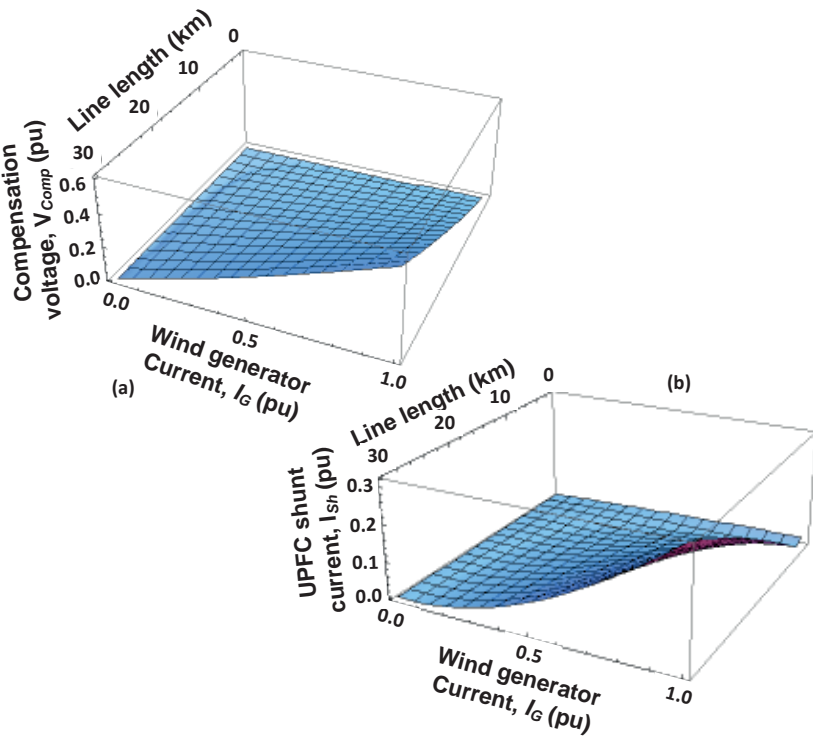

Fig. 7. (a) Compensation voltage for DVC as a function of the injected current $\left(I_{G}\right)$ by the WG and resistive line impedance. (b) UPFC shunt current, $I_{S h}$, for the same condition.

IVC and DVC alternatives can be compared in terms of the apparent power of the compensator necessary to regulate the voltage at the PCC.

In the IVC, the apparent power of the compensator per phase can be given approximately by:

$$
S_{I}=V_{P C C} I_{C o m p}
$$

where $V_{P C C} \cong 1 \mathrm{pu}$ and $I_{C o m p}$ is the compensation current imposed by the STATCOM.

In the DVC, the apparent power of the UPFC per phase is estimated by:

$$
S_{D}=V_{C o m p} I_{G}+V_{s h} I_{s h} .
$$

Considering that losses in the DC link and VSCs are negligible, (9) can be rewritten as:

$$
S_{D}=2 V_{\text {Comp }} I_{G}
$$

Table I shows the apparent power necessary to keep the PCC voltage controlled by IVC (STATCOM) and DVC (UPFC) in resistive lines.
TABLE I Apparent Power for IVC and DVC $(\mathrm{R} / \mathrm{X} \approx 4.0)$

\begin{tabular}{ccccc}
\hline & \multicolumn{2}{c}{$\mathbf{8} \mathbf{~ k m}$} & \multicolumn{2}{c}{$\mathbf{1 2} \mathbf{~ k m}$} \\
\hline$I_{G}(p u)$ & $S_{I}(p u)$ & $S_{D}(p u)$ & $S_{I}(p u)$ & $S_{D}(p u)$ \\
\hline 0.2 & 0.0 & 0.0 & 0.0 & 0.0 \\
\hline 0.4 & 0.46 & 0.088 & 0.64 & 0.134 \\
\hline 0.6 & 0.96 & 0.134 & 1.10 & 0.2 \\
\hline 0.8 & 1.44 & 0.18 & 1.48 & 0.28 \\
\hline 1.0 & 1.85 & 0.122 & 1.80 & 0.36 \\
\hline
\end{tabular}

These results indicate that the power rating of a UPFC is much lower than the power rating of a STATCOM. The series VSC of the UPFC should be rated for full line current and small percentage of the system voltage. On the other hand, the STATCOM for a maximum compensation should be rated for full system voltage and a current greater than $1.0 \mathrm{pu}$.

\section{SINGLE-PHASE VOLTAGE CONTROL WITH UPFC}

This section presents the control strategy for DVC based on single-phase UPFC units (UPFC - 1 $\phi$ ). Figure 8 shows a simplified single-phase circuit diagram of a radial feeder in a distribution grid. The shunt converter of the UPFC is connected to the grid through a coupling transformer and it is represented as a variable current source, and in this case, the series converter is directly connected in series to the grid transformer at low voltage side. The grid transformer is utilized to provide the connection point. However, this converter could be connected directly in series with the line.

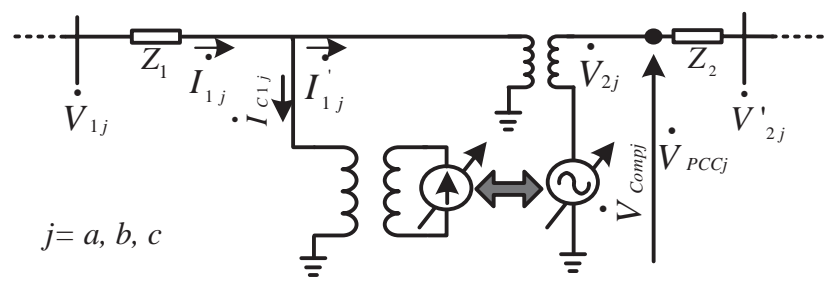

Fig. 8. Simplified single-phase circuit diagram for the analysis of the DVC based on single-phase UPFC units.

The UPFC is controlled to synthesize a series voltage in order to keep the PCC voltage at the reference value, i.e.:

$$
\dot{V}_{P C C_{j}}=\dot{V}_{2_{j}}+\dot{V}_{C o m p_{j}}
$$

where $\dot{V}_{2_{j}}(j=a, b, c)$ is the transformer secondary winding phase $j$ voltage phasor and $\dot{V}_{C o m p}$ is the compensation voltage for the corresponding phase, or:

$$
\dot{V}_{\mathrm{Comp}_{j}}=k \dot{V}_{2_{j}}
$$

where $k$ is the compensation factor. The UPFC contribution is analyzed by varying the magnitude of the compensation voltage $\dot{V}_{\mathrm{Comp}_{j}}$ for some phase angle conditions. For the direct compensation of the voltage magnitude, $k$ has real value, and $\dot{V}_{C_{o m p j}}$ is injected with $0^{\circ}$ or $180^{\circ}$ with respect to $\dot{V}_{2_{j}}$. This type of compensation is suitable for grids in which the phases of voltage at PCC may be considered balanced and the UPFC controls the voltage independently in each phase. 
In the direct compensation of the voltage magnitude and phase, $k$ has complex values, and $\dot{V}_{C o m p}$ can be injected with different phases with respect to $\dot{V}_{2_{j}}$. In this case, the compensation is suitable for grids in which the magnitudes and phases of the voltage at PCC may be considered unbalanced.

\section{A. Dynamic Control of the Series-connected VSC}

The control block diagram of the series VSC for the direct voltage magnitude compensation, for one phase, is shown in Figure 9. The rms value of the PCC voltage ( $\left.v_{P C C_{-} r m s}\right)$ is compared with its reference value $\left(v_{P C C_{-} r m s} *\right)$. The comparison result is processed by a PI controller, generating the compensation voltage magnitude, which is multiplied by the signal $\sin (\omega t)$, from the Phase Locked Loop - (PLL) [15]. In case of grid frequency variation, this single phase PLL acts tracking the fundamental component of different frequency values. A range of frequency considered in some analysis performed by the authors was from $59 \mathrm{~Hz}$ to $61 \mathrm{~Hz}$. This is greater than the recommended range in [7], that is $\pm 0.1 \mathrm{~Hz}$ for normal operation.

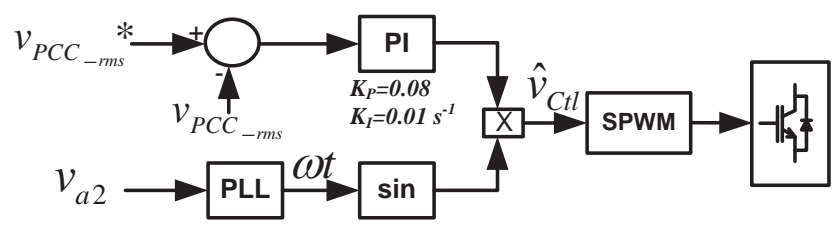

Fig. 9. Voltage control block diagram for the series VSC (magnitude compensation).

The voltage, synthesized by the VSC, is injected in series with the grid (secondary of the transformer). The switching strategy adopted for this VSC is the SPWM (Sinusoidal Pulse Width Modulation) with a switching frequency equal to $5.0 \mathrm{kHz}$.

\section{B. Dynamic Control of the Shunt-connected VSC}

Each shunt VSC is controlled as a current source in order to keep the DC-link voltage constant. The adaptive hysteresis band current control strategy was adopted for this VSC. The DC link voltage control block diagram is shown in Figure 10. The measured DC-link voltage $\left(V_{D C}\right)$ is compared with its reference value $\left(V_{D C} *\right)$. The result of this comparison is processed by a PI controller. A synchronizing circuit (PLL) provides a unity amplitude sine signal in phase with the line voltage at the point where the shunt VSC is connected. The obtained result in the output of the PI controller $\left(I_{m}\right)$ is multiplied by the sinusoid signal generating the current reference signal $\left(i_{R e f}\right)$. This current reference is compared with the shunt VSC current, generating a current error that is used to drive the hysteresis band controller. In this case, for simplicity, the switching strategy adopted is the hysteresis band current control. This way it is possible to keep the DC voltage constant controlling the current injection by shunt VSC.

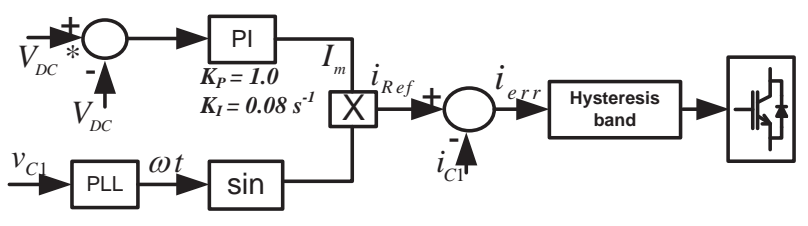

Fig. 10. Voltage control block diagram for the series VSC.

\section{SIMULATION RESULTS}

This section shows simulation studies that demonstrate the UPFC capability to control directly the voltage (DVC) in distribution networks, considering the control strategies proposed in this work. This analysis has been performed in the PSCAD/EMTDC program. The UPFC is based on single-phase VSCs and has the objective of achieving a satisfactory integration of WG into the distribution network. For this analysis, the WG operates at a unity power factor and maximum power of 1.0 MVA. In almost all cases, the voltage reference at the PCC is kept equal to $1.0 \mathrm{pu}$. However, this voltage could be maintained at any value between 0.95 and 1.05. Therefore, it could be chosen in such way s to optimize the voltage profile along the feeder. However, this study was not developed here. The generic electrical three-phase systems including these UPFCs are shown in Figure 11.

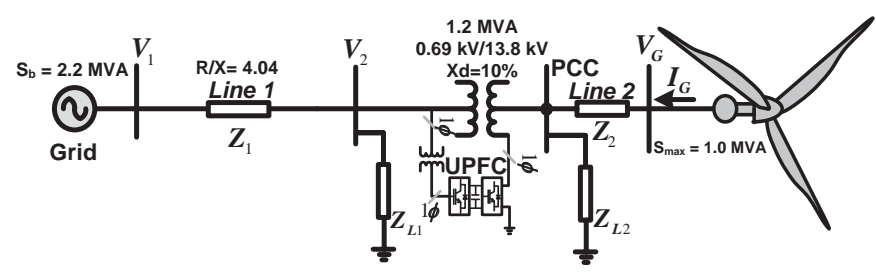

Fig. 11. Distribution network with the UPFC controlling the PCC voltage.

Figure 12 shows the voltage variation at the PCC due to the operation of the wind generator at $t=0.4 \mathrm{~s}$, injecting $0.5 M V A$. This figure indicates that the voltage at PCC rises to $1.065 p u$ which is above the acceptable limit. The UPFC operation, considering the direct compensation of the voltage magnitude, at $t=2.0 \mathrm{~s}$ brings these voltages to $1.0 \mathrm{pu}$ in approximately $100 \mathrm{~ms}$. It also shows the UPFC shunt current and its series voltage for this case. Before the compensation, the THD (Total Harmonic Distortion ) at the PCC voltage per phase is zero as the circuit is linear. With the UPFC compensation, this distortion increase to $0.0104 \%$ which is in accordance with the regulations [16].

Figure 13.a shows the PCC voltage when the load $Z_{L 2}$ is disconnected for $500 \mathrm{~ms}$. The phase voltages reach a maximum rms value of about $1.15 \mathrm{pu}$. The UPFC as shown in Figure 13.b is able to keep the PCC voltage variation within acceptable limits $( \pm 5 \%)$. The UPFC shunt current and its series voltage synthesized in this situation are shown in Figure 14.

Figure 15.a shows a variable active power injection by the wind turbine and Figure 15.b shows that the UPFC is able 


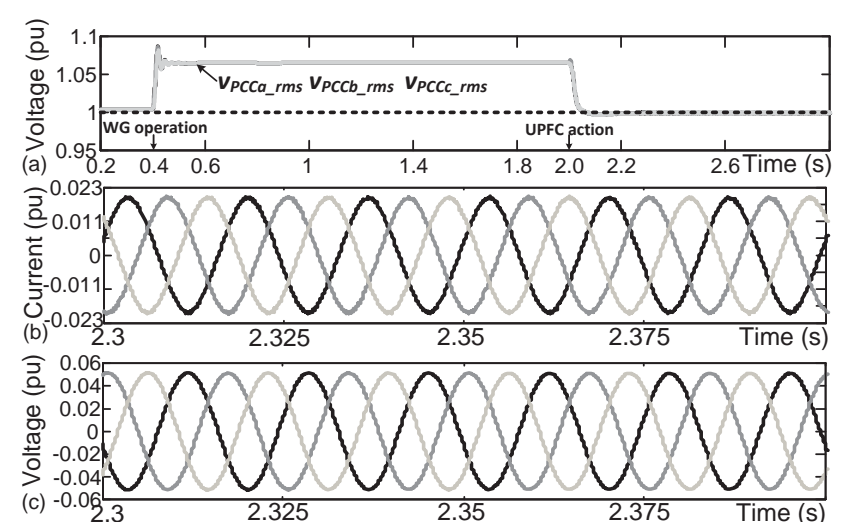

Fig. 12. (a) Result of DVC at PCC with UPFC $1 \phi-1 \phi$, (b) UPFC Shunt current and (c) Compensation voltage .
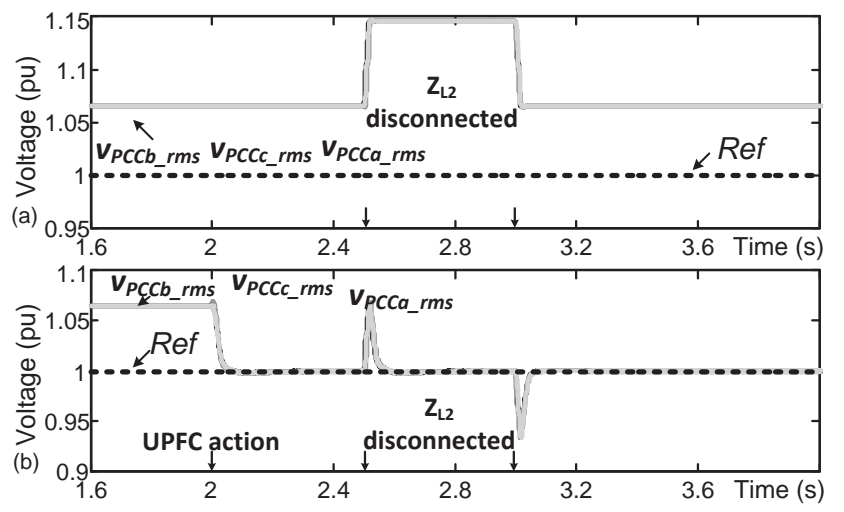

Fig. 13. Voltages at PCC when the load is disconnected/connected. (a) without UPFC and (b) with UPFC.
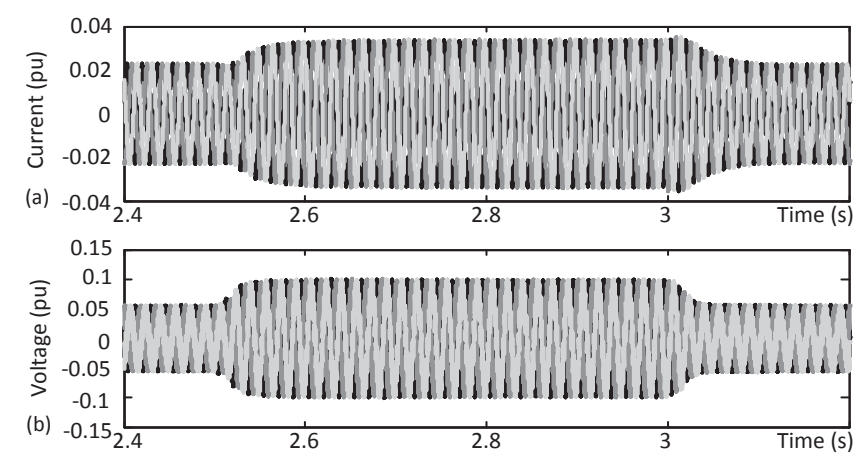

Fig. 14. (a) UPFC shunt current and (b) Compensation voltage when the load is disconnected/connected.

to keep the PCC voltage without significant variations. The UPFC shunt current and compensation voltage synthesized according to the active power injected by the WG are shown in Figure 16. As can be noted, maximum shunt current is lower than $0.032 \mathrm{pu}$ and the maximum compensation voltage is lower than $0.1 \mathrm{pu}$.

The UPFC $1 \phi-1 \phi$ performance when the voltage at PCC is unbalanced is shown in Figure 17. The voltage at phase $b$ is $5 \%$ lower than the voltage in phases $a$ and $c$. Figure 17
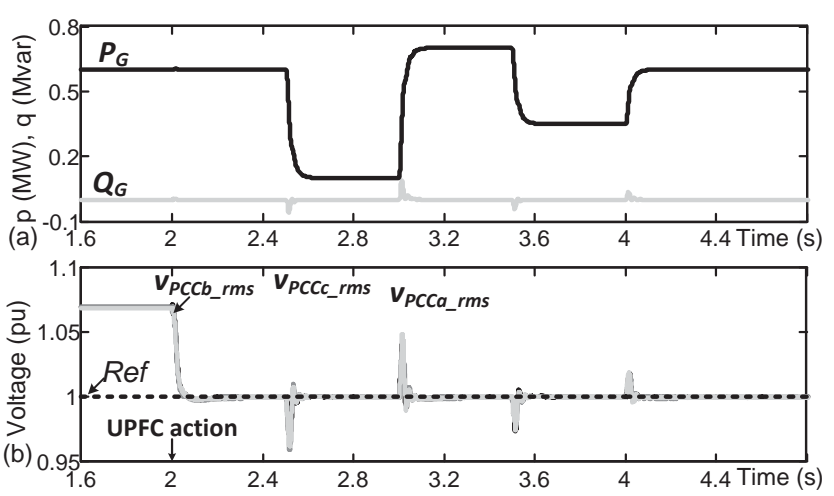

Fig. 15. (a) Wind generator active power variation and (b) PCC voltage.
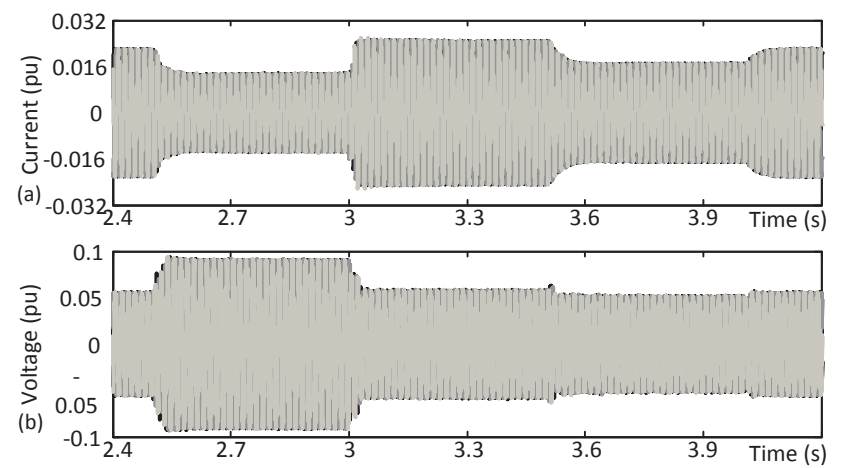

Fig. 16. (b) UPFC three-phase shunt current and (b) Compensation three-phase voltage for WG active power variation.

indicates that the voltage imbalance increases when the WG starts injecting power to the grid. In this situation, the PCC voltage unbalance is approximately $2.0 \%$. With the UPFC operation considering the magnitude compensation, the PCC voltage is regulated to the nominal value in approximately $100 \mathrm{~ms}$ and the PCC voltage unbalance is decreased to $0.036 \%$. The UPFC shunt current and the compensation voltage obtained in this situation are shown in Figure 18. Each single phase UPFC was able to control the voltage magnitude independently in each phase. Before the compensation, the THD (Total Harmonic Distortion ) at the PCC voltage per phase is zero. With the UPFC compensation, this distortion is $0.06 \%$ which is also in accordance with the regulations [16].

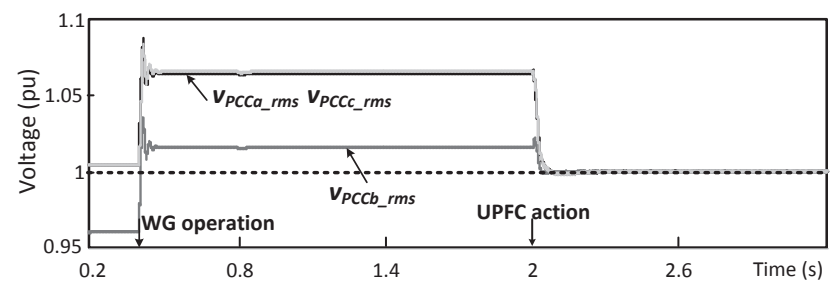

Fig. 17. UPFC $1 \phi-1 \phi$ performance with unbalanced PCC voltage.

Figure 19 shows the UPFC action for different values of the 

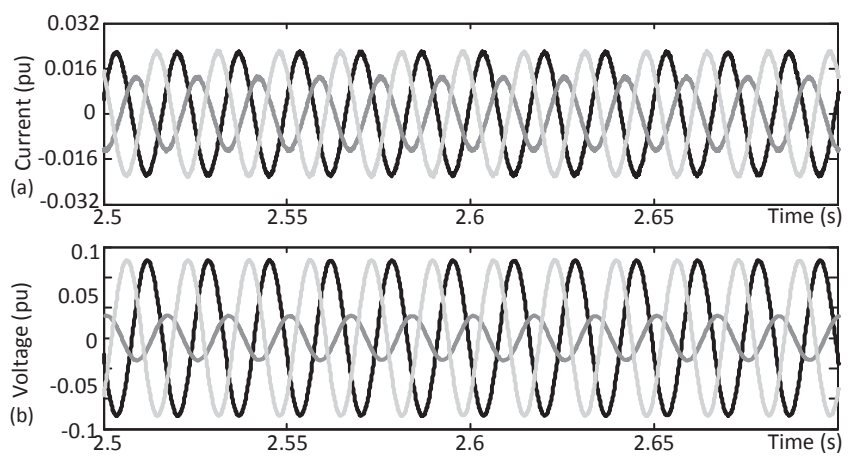

Fig. 18. (a) UPFC shunt three-phase current and (b) Compensation three-phase voltage for unbalanced PCC voltage.

PCC voltage reference. In this case, this voltage varies from $0.95 \mathrm{pu}$ to $1.05 \mathrm{pu}$. The UPFC acts efficiently maintaining the PCC voltage at the different values. This way, it possible to optimize the voltage profile along the feeder.

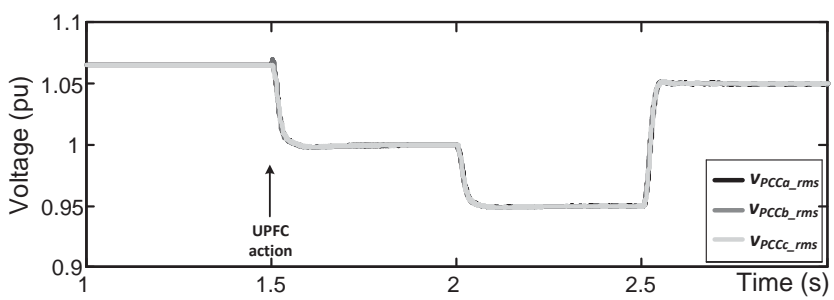

Fig. 19. UPFC action for different voltage reference values at the PCC.

\section{CONCLUSION}

In this paper, studies have been conducted to investigate the impact of intermittent distributed generation. The Indirect Voltage Control and the Direct Voltage Control were discussed and compared. Simulation results show that DVC can be an excellent alternative to improve the voltage profile at the PCC of the distribution grids with wind generation in terms of equipment rating. In this context, UPFCs based on single-phase VSCs are proposed to mitigate the impact of the aforementioned sources, regulating the voltage at the PCC of the distribution grids even if voltage magnitude is unbalanced.

The PRODIST [17] set that in case of distributed generation, the local utility should bear the spending of reconductoring feeders in the distribution system. In other words, if the feeder is working close to its limit, presenting, for instance, large variations of voltage, the feeder should be replaced with one of higher capacity. The proposed UPFC is presented as a solution that aims to reduce costs and increase operational flexibility of the grid with respect to the voltage profile.

Of Course, the proposed solution implies in the insertion of the series converter in the feeder. This is not a solution normally accepted by the utilities. However, if the intermittent generation is to be connected to the grid, the proposed solution should be compared with the reinforcing (reconducting or increase the voltage level) or using indirect voltage control (STATCOM or SVC). The authors believe that the use of UPFC for the direct voltage control may be a technically and cost affective solution solution in some case.

It was shown that the proposed UPFC is able to keep the voltage profile at the PCC at the nominal value with compensation rating lower than when conventional reactive power control is used. In fact, the conventional reactive power control for indirect voltage regulation may be ineffective as compared to DVC. The authors are investigating control strategies for the case of unbalances in the voltage magnitude and phase.

\section{ACKNOWLEDGEMENT}

This work was partially supported by CNPq (305114/20093) and FAPERJ (E-26/ 102.974/2011).

\section{REFERENCES}

[1] H. Laaksonen, P. Saari, R. Komulainen. "Voltage and frequency control of inverter based weak LV network microgrid", In Future Power Systems, 2005 International Conference on, doi 10.1109/FPS.2005.204293, pp. 1-6, 2005.

[2] W. Sahan J. P. da Costa, W. Kruschel, P. Zacharias. "Power electronics for voltage control in distribution networks", In 16th Kassel Symposium Energy Systems Technology, pages 1-15, 2011.

[3] S. L. S. L. Barcelos, “UPFC para Controle de Tensão”. Tese de Doutorado, Universidade Federal do Rio de Janeiro (UFRJ), Rio de Janeiro-RJ, 2013.

[4] S. L. S. Lima, E. H. Watanabe. "Estudo de UPFC baseado em conversores monofásicos" In Simpósio Brasileiro de Sistemas Elétricos, pp. 1-7, Belém-PA, Maio, 2010.

[5] S. L. S. Lima, E. H. Watanabe. "UPFC based on single-phase converters for voltage control" In Power Electronics Conference (COBEP), 2011 Brazilian, pp. 107-113, 2011.

[6] S. L. S. Lima, E. H. Watanabe. "Direct Voltage Control in Grids with Intermittent Sources Using UPFC" In Power Electronics Conference (COBEP), 2013 Brazilian, pp. 18, 2013.

[7] IEEE Application Guide for IEEE STD 1547, IEEE Standard for interconnecting distributed resources with electric power systems. IEEE Std 1547.2-2008, pp. 1207, 2009.

[8] G. P. Harrison T. Sansawatt, L. F. Ochoa. "Integrating distributed generation using decentralised voltage regulation", In IEEE Power and Energy Society General Meeting, 2010, pp. 25-29, July, 2010.

[9] V. B. Virulkar, M. V. Aware. "Mitigation of flicker at wood saw machine with active and reactive power compensation" In International Conference on Power Systems, 2009. ICPS '09., pp. 1-6, 2009.

[10] A. Ortiz, T. Ostrem, W. Sulkowski. "Indirect negative sequence voltage control for statcom supporting wind farms directly connected to the grid", In IECON 2011 
- 37th Annual Conference on IEEE Industrial Electronics Society, pp. 1903-1908, 2011.

[11] T. L. Lee, S. H. Hu, Y. H. Chan. "D-Statcom with positive-sequence admittance and negative-sequence conductance to mitigate voltage fluctuations in high-level penetration of distributed-generation systems", IEEE Transactions on Industrial Electronics, 60(4):14171428, 2013.

[12] K. Sen, M. Sen. "Introduction to FACTS Controllers: Theory, Modeling and Applications”, volume 1a Edição. IEEE PRESS, USA, 2009.

[13] B. Gwisdorf, T. Borchard, T. Hammerschmidt, C. Rehtanz. "Technical and economic evaluation of voltage regulation strategies for distribution grids with a high amount of fluctuating dispersed generation units", In Innovative Technologies for an Efficient and Reliable Electricity Supply (CITRES), 2010 IEEE Conference on, pp. 8-14, 2010.

[14] N. G. Hingorani, L. Gyugyi. "Understanding FACTS: Concepts and Technology”. IEEE PRESS, USA, 2000.

[15] M. Karimi-Ghartemani, M. R. Iravani. "A new phaselocked loop (PLL) system", In Circuits and Systems, 2001. MWSCAS 2001. Proceedings of the 44th IEEE 2001 Midwest Symposium on, volume 1, pages 421 - 424 vol.1, 2001.

[16] IEEE Recommended Practices and Requiriments for Harmonic Control in Electrical Power Systems. IEEE Std 519 - 1992, New York, 1992.

[17] ANEEL. Procedimentos de Distribuição de Energia Elétrica no Sistema Elétrico Nacional. PRODIST Módulo 8: Qualidade da Energia Elétrica, 2010.

\section{BIOGRAPHIES}

Silvangela Lilian da Silva Lima was born in São Luís$\mathrm{MA}$, Brazil, in 1980. She received the B.Sc. degree in Electrical Engineering from the Federal University of the Maranhão and the master degree in electrical engineering from the Federal University of Rio de Janeiro (UFRJ) in 2007.
She received the Ph.D degree in Electrical Engineering from the Federal University of of Rio de Janeiro (UFRJ) in 2013. Currently she works with electrical engineering department at UFRJ as a researcher. Her main research area includes FACTS performance in transmission and distribution systems and renewable generations (wind and solar).

Robson Francisco da Silva Dias was born in Rio de Janeiro, Brazil, in 1978. He received the B.Sc. degree in Electrical Engineering from the Federal University of Pará and Ph.D. degree in electrical engineering from the Federal University of Rio de Janeiro (UFRJ), in 2002 and 2008, respectively. Currently his is a associate professor with electrical engineering department at UFRJ. His main research area includes FACTS technologies, transmission lines and electromagnetic transient studies.

Edson Hirokazu Watanabe got the Electronic Engineering and Master in Electrical Engineering degrees, in 1975 and 1976, respectively, from Federal University of Rio de Janeiro. In 1981, he got the Doctor of Engineering (D. Eng.) from Tokyo Institute of Technology, Japan. Since 1981, he is a professor at the Electrical Engineering Department, COPPE / Federal University of Rio de Janeiro. He has supervised 50 Master and 21 Doctors Thesis. His field of interest is Power Electronics Applied to Power Systems, including renewable generations (wind, solar and wave). He is one of the co-authors of the book "Instantaneous Power Theory and Applications to Power Conditioning", published by IEEE Press /Wiley. Dr. Watanabe is a member of IEEJapan, The Brazilian Society for Automatic Control, The Brazilian Power Electronics Society, CIGRE and PE, PEL and IA Societies of IEEE. He is a member of the National Academy of Engineering and received the 2013 IEEE-PES Nari Higorani FACTS Award. 